\title{
Allomaternal care, life history and brain size evolution in mammals
}

\author{
Isler, $\mathrm{K}$; van Schaik, C P
}

\begin{abstract}
Humans stand out among the apes by having both an extremely large brain and a relatively high reproductive output, which has been proposed to be a consequence of cooperative breeding. Here, we test for general correlates of allomaternal care in a broad sample of 445 mammal species, by examining life history traits, brain size, and different helping behaviors, such as provisioning, carrying, huddling or protecting the offspring and the mother. As predicted from an energetic-cost perspective, a positive correlation between brain size and the amount of help by non-mothers is found among mammalian clades as a whole and within most groups, especially carnivores, with the notable exception of primates. In the latter group, the presence of energy subsidies during breeding instead resulted in increased fertility, up to the extreme of twinning in callitrichids, as well as a more altricial state at birth. In conclusion, humans exhibit a combination of the pattern found in provisioning carnivores, and the enhanced fertility shown by cooperatively breeding primates. Our comparative results provide support for the notion that cooperative breeding allowed early humans to sidestep the generally existing trade-off between brain size and reproductive output, and suggest an alternative explanation to the controversial 'obstetrical dilemma'-argument for the relatively altricial state of human neonates at birth.
\end{abstract}

DOI: https://doi.org/10.1016/j.jhevol.2012.03.009

Posted at the Zurich Open Repository and Archive, University of Zurich ZORA URL: https://doi.org/10.5167/uzh-63501

Journal Article

Published Version

Originally published at:

Isler, K; van Schaik, C P (2012). Allomaternal care, life history and brain size evolution in mammals. Journal of Human Evolution, 63(1):52-63.

DOI: https://doi.org/10.1016/j.jhevol.2012.03.009 


\title{
Allomaternal care, life history and brain size evolution in mammals
}

\author{
Karin Isler*, Carel P. van Schaik \\ Anthropological Institute and Museum, University of Zurich, Winterthurerstrasse 190, CH-8057 Zurich, Switzerland
}

\section{A R T I C L E I N F O}

\section{Article history:}

Received 31 January 2012

Accepted 31 March 2012

Available online 10 May 2012

\section{Keywords:}

Cooperative breeding

Helping behaviors

Fertility

Brain growth

Eutherian mammals

\begin{abstract}
A B S T R A C T
Humans stand out among the apes by having both an extremely large brain and a relatively high reproductive output, which has been proposed to be a consequence of cooperative breeding. Here, we test for general correlates of allomaternal care in a broad sample of 445 mammal species, by examining life history traits, brain size, and different helping behaviors, such as provisioning, carrying, huddling or protecting the offspring and the mother. As predicted from an energetic-cost perspective, a positive correlation between brain size and the amount of help by non-mothers is found among mammalian clades as a whole and within most groups, especially carnivores, with the notable exception of primates. In the latter group, the presence of energy subsidies during breeding instead resulted in increased fertility, up to the extreme of twinning in callitrichids, as well as a more altricial state at birth. In conclusion, humans exhibit a combination of the pattern found in provisioning carnivores, and the enhanced fertility shown by cooperatively breeding primates. Our comparative results provide support for the notion that cooperative breeding allowed early humans to sidestep the generally existing tradeoff between brain size and reproductive output, and suggest an alternative explanation to the controversial 'obstetrical dilemma'-argument for the relatively altricial state of human neonates at birth.
\end{abstract}

(c) 2012 Elsevier Ltd. All rights reserved.

\section{Introduction}

Humans are characterized by a high level of allomaternal care (e.g., Hrdy, 2009), which has been proposed as the original catalyst for many later steps in hominization (Hrdy, 2005; Burkart et al., 2009; see also Aiello and Wells, 2002). The cooperative breeding hypothesis (Hrdy, 2009) claims that psychological characteristics such as proactive prosocial (or other-regarding) preferences arose as a result of cooperative breeding, since they are also found in cooperatively breeding callitrichids (Burkart and van Schaik, 2010). We have also argued that cooperative breeding in early hominins, through energy subsidies for mothers and weaned children, may have allowed for the steep increase in encephalization (Isler and van Schaik, 2009a; Navarrete et al., 2011), without a concurrent reduction of the rate of reproduction. This claim warrants substantiation.

Here, we use a broad comparative approach to test predictions concerning the effect of allomaternal care on brain size derived from an energetic framework (Isler and van Schaik, 2009a), which argues that the growth and maintenance of brain tissue (Mink et al., 1981) usurp a considerable proportion of an animal's energy

\footnotetext{
* Corresponding author.

E-mail addresses: kisler@aim.uzh.ch (K. Isler), vschaik@aim.uzh.ch (C.P. van Schaik).
}

budget. Because reproduction is also energetically expensive (e.g., Zenuto et al., 2002; McNab, 2006; Speakman, 2008), Isler and van Schaik (2009a) argued that one major pathway toward the evolution of larger brains was reduced allocation to growth and reproduction ('production' in Charnov, 1993). Indeed, among altricial mammals, increased brain size (always assuming constant body mass) is correlated with reduced litter size, whereas among precocial mammals, mostly producing singletons, it is instead correlated with reduced birth rate (Isler and van Schaik, 2009a). The young of relatively large-brained precocial species develop more slowly and attain sexual maturity at a later age than young of relatively small-brained species. Moreover, all larger-brained mammals produce relatively larger neonates, which may buffer against the serious long-term effects of starvation or malnutrition on brain development and functioning (for humans, e.g., Kar et al., 2008; reviewed in Levitsky and Strupp, 1995). Not surprisingly, therefore, we also found that relatively large-brained mammals have reduced annual fertility. All of these effects of brain size add up to produce a strong negative correlation between brain size and maximum possible population growth rate $\left(r_{\max }\right.$; Isler and van Schaik, 2009b). Because of this trade-off between brain size and reproductive output, the basic prediction is that the evolution of allomaternal care in a lineage facilitates an evolutionary increase in either brain size, by allowing greater energy allocation to the brain, fertility, or both (albeit each to a lesser extent), in comparison to its independently breeding relatives. 
Allomaternal inputs (henceforth 'help') are found in many eutherian mammals, comprising behaviors such as provisioning, carrying, huddling or communal nesting, babysitting, and protection from predators or defense of resources against conspecifics. This help is therefore a mix of (direct or indirect) energetic inputs and general protection. Its effects on offspring survival or fertility have been demonstrated within species (e.g., reviewed in Snowdon, 1996; Silk, 2007), and also between carnivore species (Gittleman and Oftedal, 1987; Moehlman and Hofer, 1997). One likely mechanism underlying this effect is load-lightening of lactating females by helpers, which has been demonstrated e.g., for meerkats (Suricata suricatta) (Scantlebury et al., 2002) and for primates, in which fathers and older siblings carry their offspring (callitrichids: Garber and Leigh, 1997; Bales et al., 2000; siamangs: Lappan, 2009). In communal breeders, other adults, usually reproducing females, provide the help through babysitting or allonursing (Packer et al., 1992). This support may reduce peak maternal loads (König, 2006) and load-lighten mothers also on average, if the provided care is non-depreciable, i.e., that the costs of huddling or babysitting do not increase with the number of offspring (Clutton-Brock, 1991). In sum, there is ample empirical evidence that distributing the costs of reproduction over several (or at least two) individuals yields an energetic benefit for mothers.

Previous studies of the relation between allomaternal care and brain size have reported mixed results. Gittleman (1994) found that independently breeding carnivore mothers have relatively larger brains than communal or biparental breeders. On the other hand, species in those carnivore families that are characterized by frequent occurrence of helping behaviors (Canidae, Herpestidae, and Hyaenidae) formed an exception to the rule that larger-brained mammals have lower fertility (Isler and van Schaik, 2009a). For primates, Ross (2003) quantified allomaternal care according to percentage of time spent with conspecifics other than the mother, and found a negative correlation between the amount of allomaternal care and brain size. In marsupial mammals, species that exhibit allomaternal care have relatively larger brains than solitary species or species that live gregariously without showing allomaternal care (Isler, 2011). In corvid birds, cooperative breeders are not relatively larger-brained than pair-breeding species (Iwaniuk and Arnold, 2004). Most of these studies, however, relied on a categorical distinction between species with and without help, whereas from an energetic perspective the actual amount of allomaternal care may be more important.

The aim of this paper is therefore to quantitatively examine the effect of various helping behaviors on fertility and relative brain size in eutherian mammals as a whole as well as in various speciose radiations within this taxon. We do not expect this prediction to differ between precocial and altricial mammals, because help is not only effective during the period of brain growth (i.e., mainly during gestation in precocials and during lactation in altricials, cf. Dobbing and Sands, 1979), but also during the period when the offspring's brains are much larger relative to body mass than in adults, and thus proportionally much more expensive (i.e., during lactation in precocials). Thus, we expect that the energetic effects of allomaternal care allow mothers to increase fertility or relative brain size in both altricials and precocials (prediction 1). Beyond this general prediction, we also predict that the strength of the effect decreases from those helping behaviors that provide a direct energetic benefit, such as provisioning, to more indirect benefits that reduce the mother's burden such as carrying, huddling, or babysitting, to potential benefits such as protection (prediction 2).

However, the amount of help may also affect the developmental stage at birth. On one hand, a shift toward more altricial offspring would increase the effectiveness of help, by resulting in a reduced load for the mothers during gestation. Thus, in a bird species, the superb fairy-wren (Malurus cyaneus), mothers laid smaller eggs in the presence of helpers, and subsequently exhibit increased survival rates (Russell et al., 2007). For mammals, only those precocial taxa that are able to shelter their offspring from predation, such as primates, should be able to afford such a shift toward more altricial offspring (prediction 3). On the other hand, if help mainly increases the survival rate of offspring, a quality-overquantity strategy should be more successful and we predict a shift toward fewer, but more precocial offspring (prediction 4).

We test these predictions using a large sample of 445 eutherian mammal species, for which there is reliable information on brain and body mass, as well as the nature and extent of allomaternal help. We first investigate the clustering of the different helping behaviors, and their distribution among various mammalian clades. We subsequently analyze the effect of these components of help on both brain size and life history variables, while controlling for the effects of phylogenetic relatedness and several potential covariates. In particular, since a positive correlation between brain size and allomaternal care could also arise from a social effect (the 'social brain hypothesis', e.g., Dunbar, 2009), and because cooperative care requires a social lifestyle, we include gregariousness as a covariate in all analyses to disentangle the potential effects of social settings and allomaternal care.

\section{Methods}

\section{Data}

The full dataset is available as SOM. Taxonomy follows Groves (2005) for primates and Wilson and Reeder (2005) for all other mammals. Data on brain and body mass as well as life history parameters of eutherian mammals were compiled from various sources (the compilation is described in detail in Isler and van Schaik, 2009a). If available, we used sex-specific values, preferring female to male values. If sex-specific values for brain size were not available for a species, but sexual dimorphism in body mass is reportedly pronounced (more than $10 \%$ difference), we used the body mass of the smaller sex, usually female, to reduce error variation.

Values on allomaternal care behavior and ecological variables were compiled from published compilations (Spencer-Booth, 1970; Gubernick and Klopfer, 1981; Dewsbury, 1985; Whitten, 1987; Bronson, 1989; Emlen, 1991; Packer et al., 1992; Gittleman, 1994; Woodroffe and Vincent, 1994; Snowdon, 1996; König, 1997; Solomon and French, 1997; Hayes, 2000; Ross and MacLarnon, 2000; Silk, 2007; Wilson and Mittermeier, 2009), the Mammalian Species accounts (1969-2009), reliable online sources (Animal Diversity Web, Myers et al., 2006) and original sources for individual species (for a full list of references, see SOM).

In total, data on helping behavior and brain size were available for 445 species of eutherian mammals. Chiroptera and Cetacea were excluded from being sampled because reliable data on allomaternal care and life history characteristics of both cetaceans and bats are notoriously difficult to obtain (see SOM for a discussion). Eusocial bathyergid rodents were not included as it was not clear from published records of brain size and body mass data (Mace et al., 1981) whether the size dimorphism between reproductive and non-reproductive adults was adequately considered.

\section{Helping behavior}

We need a measure of help that reflects energetic inputs to the mother or her offspring. For our purposes, it does not matter here whether helping behavior is costly for the donor, whether the help is depreciable (Clutton-Brock, 1991) or not, or whether there is 
reproductive skew or not. However, it may well matter what kind of help is provided: carrying, provisioning, allonursing, thermoregulation, protection from predators, or defense of feeding range (the latter two may indirectly improve maternal energy budgets). Thus, helping behavior was divided into the following categories: carrying, provisioning, allonursing, thermoregulation/babysitting and protection. Carrying and provisioning, as the energetically most costly behaviors, were recorded separately for the father and other group members. We aimed at obtaining a quantitative measure of these helping behaviors by considering their frequency of occurrence (results using an alternative, categorical coding scheme are generally similar, see SOM). If the published records of allomaternal help were vague regarding these frequencies, we put the emphasis on adequately reflecting the difference between closely related species in our values, as this difference is most relevant in a phylogenetic comparative approach. Thus, the difference or similarity of a value between sister taxa is much more robust and reliable than the absolute values. Coding was done in order to yield variables between 0 and 1 as follows:

Provisioning by the male This refers to the frequency of provisioning by the male (usually, the breeding male in pair-living species, but, rarely, any adult male in polygynous or multi-male, multi-female groups). It was set to 1 , if the male usually actively shared or provisioned food, to 0.75 if passive sharing was more frequent $(70-80 \%)$ but active sharing was common $(20-30 \%)$, to 0.5 if passive sharing was common and active sharing rare, to 0.1 if passive sharing was rare, and to 0.05 if single observations of food sharing or provisioning were reported.

Provisioning by others The frequency of provisioning or food sharing by other group members was assigned using the same scoring system as for the male.

Carrying by the male This refers to the frequency of carrying by the male. If the offspring was carried $50 \%$ of the time by the male, the value was 0.5 . When carrying behavior was limited to pup retrieval it was counted in the category of thermoregulation, etc. below.

Carrying by others The frequency of carrying by other group members was assigned using the same distinctions as for the male. Protection This refers to the occurrence of active protection by the male, defense of territory, or defense against predators. It was considered absent if territories were only protected against other males, and females or young may even be hurt during agonistic encounters between males. Otherwise, we scored protection as 1 if it was usual, 0.5 if frequent, 0.1 if rare, and 0.05 if single observations were reported. If more precise values were given in the original sources, those were used.

Thermoregulation, babysitting and pup retrieval This refers to the occurrence of babysitting during the mother's absence, retrieving pups, or carrying offspring to a new nest, by the male or other group members, huddling, and communal nesting (together with male or other females, breeding or non-breeding) during the breeding period. It was scored as follows: 1 if it was usual, 0.5 if frequent, 0.1 if rare, and 0.05 if single observations were reported. If more precise values were given in the original sources, those were used.

Communal nursing (allonursing) This refers to the frequency of allonursing of an infant. The values given by Packer et al. (1992) were converted as follows: ' 1 ' $(<10 \%)$ was set to 0.1 , ' 2 ' $(10-45 \%$, less than own mother) to 0.25 , and ' 3 ' (as much as own mother) to 0.5 . If more precise values were given in the original source, these were used.

If a behavior is only shown during part of the period of offspring dependence, the value was weighted accordingly (e.g., in Symphalangus syndactylus, the male is carrying the offspring $100 \%$ for one year out of a total of two; thus the value for male carrying was set to $0.5)$. Finally, if a species was described as solitary and territorial, or aggressive against conspecifics (often most pronouncedly during the breeding period), all help values were set to zero.

Provisioning of mothers This behavior was classified as 0: absent, or 1: occurring. Scoring was this crude because frequencies were not reported in the literature.

\section{Covariates}

In large-scale comparative analyses, the potential effects of hidden variables, which may cause spurious correlations between the variables of interest, are considered, if feasible, by including these variables as covariates in the analyses. For example, living in social groups could be the underlying factor responsible for a positive correlation between brain size and allomaternal care, and we therefore included gregariousness as a covariate to control for this effect. Living in social groups ('gregariousness') was classified as follows: 0 : solitary (or mother with infants), 0.5 : usually solitary, but occasionally seen in pairs or groups, or facultative group denning, 1: pairs (with infants), 1.5: usually in pairs, but gregarious at times or in part of the range, 2: permanently gregarious (the group comprises more adults than just the parents).

Diet quality, activity pattern, and substrate use have also all been suggested to correlate with relative brain size (e.g., Harvey et al., 1980; Harvey and Bennett, 1983; Harvey and Purvis, 1999), in Primates (Fish and Lockwood, 2003; Kirk, 2006), Carnivora (Gittleman, 1986), and Rodentia (Bernard and Nurton, 1993), and although it is less clear how these variables could be related to allomaternal care or fertility, we also included them as covariates. Since we were not aiming to explain the ecological correlates of brain size evolution, but rather aimed to control for them, diet quality, nocturnality and substrate use were coded empirically in a way so as to explain as much of the variation in brain size as possible (see SOM).

Although some variables were found to have significant effect on brain size in some groups, on the whole, controlling for these variables did not affect the level of significance of the results for helping behavior. This can be attributed to the use of phylogenetic methods, which are known to reduce the influence of possible confounding variables as these are usually also similar between closely related taxa (Nunn and Barton, 2001).

\section{Analyses}

As a data reduction technique to tease out patterns from sets of highly correlated variables, we applied Principal Components Analyses (PCA) to the set of allomaternal care variables, using JMP 7 (Inc. 1989-2009). Varimax rotation was applied to those factors with eigenvalues larger than one. In comparative analyses, the problem of different degrees of relatedness between species must always be addressed (Felsenstein, 1985). Therefore, we also ran a phylogenetic PCA (PPCA) using R code from Revell (2009) and the $\mathrm{R}$ package GPArotation (Bernaards and Jennrich, 2005). As the eigenvalues of the phylogenetic principal components were all very low, the phylogenetic PCA was not useful as a means of reducing the complexity of the data, but the results can still be used to investigate the robustness of our results from the species-level PCA. Therefore, the results of phylogenetic PCA are reported in the SOM only.

All morphological and life history variables were logtransformed before analysis. The correlations of the help factors with brain size or life history traits were analyzed with multiple linear regression models. To control for the effects of other variables known to exhibit correlations with brain size or life history traits in at least some taxa, adult female body mass, diet, activity period, substrate use, and gregariousness were included as 
covariates. To incorporate an empirical estimation of the degree of phylogenetic relatedness in the data, which is represented by the parameter lambda, phylogenetic general linear models (PGLS) are commonly applied (Nunn, 2011). We used the caper package in $\mathrm{R}$ (Orme et al., 2011) to fit models that control for phylogenetic relatedness, estimating lambda by maximum likelihood. Phylogenetic relationships and molecular branch length estimations were taken from the species-level supertree of Bininda-Emonds et al. (2007), refined and supplemented by more recent molecular phylogenies as listed in the SOM. However, to illustrate our findings, species or suborder mean values and residuals from nonphylogenetic multiple least-squares regressions are shown in the figures.

All analyses were conducted on three levels: in the combined sample of placental mammals $(N=445$ species), within large orders of similar lifestyle (fissiped Carnivora $(N=101)$, Rodentia $(N=113)$, Primates $(N=98)$, and Artiodactyla $(N=66))$, and on the level of suborders $(N=28$ suborder means). The latter provides a valuable alternative to investigate the contributions of small clades that are usually swamped by the larger clades in phylogenetic models. The effect of provisioning of mothers could be investigated only in Carnivora, as it is not reported in other nonhuman mammals.

\section{Results}

\section{Prevalence of helping behaviors}

Fig. 1 illustrates the distribution of helping behaviors during breeding in eutherian mammals. Provisioning is most frequent in Carnivora and Primates and almost absent in other groups. Protection by the male, in the absence of any other help, is observed in about $20 \%$ of primates and artiodactyls. Allonursing without any other form of help is mainly found in artiodactyls and in pinniped carnivores. Overall, primates stand out in that some form of helping behavior is almost ubiquitous, whereas it occurs in less than half of the species in the other groups.

\section{Components of help}

To obtain a simplified and orthogonal set of variables representing allomaternal help, we ran a Principal Components Analysis (PCA) on the components of help. The PCA yielded two principal components (Table 1). The first factor is loading on all helping behaviors except communal nursing, and is therefore referred to as 'allocare', whereas the second factor 'allonursing' is loading mainly on communal nursing.
Within the major orders, the clustering of helping behaviors differs according to lifestyle (Table 2). In Carnivora, the first factor loads most strongly on protection and provisioning by the male, but also on pup retrieval and babysitting, while provisioning by other group members groups with allonursing score high on the second factor. In Rodentia, the first factor loads on provisioning, whereas allonursing groups with communal nesting and protection score high on the second factor. In Primates, the first factor is dominated by provisioning, but comprises all allomaternal care behaviors except allonursing, which loads on the second factor. In Artiodactyla, allonursing and babysitting both load on the first factor, whereas the second factor represents protection by the male. In sum, the distinction between allonursing and the other helping behaviors is not as clear as in the combined mammalian sample, and we also need to analyze the large orders separately to investigate the effects of the components of helping behaviors on brain size and life history traits in detail.

\section{Allomaternal care and brain size}

In placental mammals as a group, the first principal component of help (cf. Table 1) is positively correlated with brain size on the level of suborders, controlling for phylogenetic relationship, body mass, gregariousness, diet, nocturnality and substrate use (Table 3A, Fig. 2). However, no significant correlation between help and brain size is found in a phylogenetic species-level analysis (Table 3B), because the relationships within some large orders exhibit opposite trends (Table 3C).

Relationships within the large orders are illustrated in Fig. 3. In terrestrial Carnivora, both factors of help are significantly positively correlated with brain size (Fig. 3A, note that non-phylogenetic regression models do not show the positive effect of allonursing), while gregariousness shows a weak negative trend. In Rodentia (Fig. 3B), the first factor, provisioning, is positively correlated to brain size and the second one, communal nesting and protection, shows a positive trend. A look at the results of the phylogenetic PCA reveals that in this order protection is positively correlated with brain size, whereas communal nesting/babysitting/pup retrieval is not (see SOM, Table S3). Thus Fig. 3B depicts the phylogenetic principal component 'protection'. In Primates (Fig. 3C), allonursing is positively correlated with brain size, but other help such as provision and carrying is negatively correlated with brain size in the phylogenetic models. In Artiodactyla (Fig. 3D), the first factor comprising allonursing and babysitting shows a very weak positive trend with brain size $(p=0.185)$, and gregariousness also shows a positive trend.

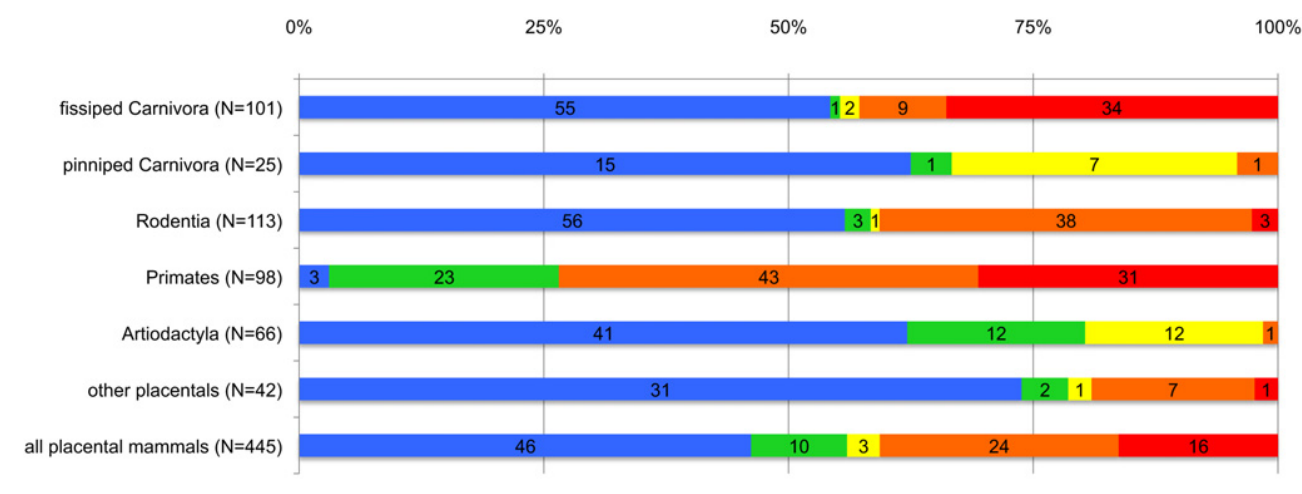

" no help " only protect $=$ only allonursing " all other forms of help, but without provisioning $~=$ with provisioning

Figure 1. Prevalence of helping behaviors within mammalian groups ( $N=445$ species). Numbers indicate number of species known to show the behavior. 
Table 1

Principal components analysis of helping behaviors in placental mammals.

\begin{tabular}{|c|c|c|c|c|c|c|c|c|c|c|}
\hline & \multirow{3}{*}{ Label } & \multirow{3}{*}{ Eigenvalue } & \multirow{3}{*}{ \% Var. expl. } & \multicolumn{7}{|c|}{ Rotated factor loadings } \\
\hline & & & & \multirow[t]{2}{*}{ Allonursing } & \multirow[t]{2}{*}{ Comm. nesting/babysit/retrieval } & \multirow[t]{2}{*}{ Protect } & \multicolumn{2}{|c|}{ Provision } & \multicolumn{2}{|c|}{ Carry } \\
\hline & & & & & & & Male & Others & Male & Others \\
\hline PC1 & Allocare & 3.333 & 47.6 & 0.112 & 0.675 & 0.720 & 0.840 & 0.801 & 0.726 & 0.672 \\
\hline PC2 & Allonursing & 1.132 & 16.2 & 0.858 & 0.318 & 0.187 & 0.097 & 0.191 & -0.362 & -0.319 \\
\hline
\end{tabular}

Factor loadings $>0.5$ are shown in bold face.

In sum, allomaternal energy inputs are correlated with brain size in mammals overall (on the suborder level), and in three out of four large orders. Whereas the effect is mostly positive, the direction is opposite for 'allocare' in primates. In all groups, the effect of direct help such as provisioning or carrying is stronger than that of indirect help such as babysitting, huddling, or protection.

\section{Allomaternal care and fertility}

In mammals as a group, on the level of suborders only the second principal component of help (cf. Table 1) was positively correlated with fertility (Table 4A and B). Again, the phylogenetic linear regression models testing the effects of helping behavior on fertility include potentially confounding variables as covariates (body mass, gregariousness, diet, nocturnality and substrate use). On the species-level, and within Primates (Table 4C), we find a positive effect of the first factor, 'allocare', on fertility. This positive effect is stronger than the simultaneous positive effect of gregariousness on fertility. In fissiped Carnivora, the second factor, 'allonursing', shows a positive trend with fertility. Overall, help is less frequently correlated with fertility than with brain size, and the two effects are complementary.

\section{Allomaternal care, development and longevity}

Analyses of other life history traits are summarized in Table 5. In mammals as a group, on the suborder level there are no significant correlations. On the species-level, the only significant correlation is found between allomaternal care (PC1) and maximum lifespan. Within orders, in Primates, allocare (PC1) is negatively correlated with gestation length and the length of the lactation period, whereas gestation length is positively correlated with provisioning (PC1) in Rodentia, and with protection (PC2) in Artiodactyla (again, as above, controlling for potentially confounding effects and phylogenetic relationships). Gregariousness is associated with a later weaning age in Carnivora, but an earlier one in Rodentia. The age at first reproduction is not related to helping behaviors in any group, but more gregarious species mature later in Artiodactyla. Maximum lifespan is positively correlated with allonursing (PC2) in Primates and shows a positive trend with PC1 in Rodentia. Overall, then, where help affects life history, it most commonly affects the earliest stage of development, gestation, suggesting that it modifies the lineage's modal developmental state at birth (precociality or altriciality), but it does not do so in the same direction in each clade.

\section{Provisioning of mothers}

In Carnivora, we could also test for the effect of provisioning the mother in those species that provision their offspring. We found that provisioning of mothers is an additional positive effect on brain size (Table 6), but does not affect the life history variables.

\section{Discussion}

The mammalian pattern

Using a large compilation of frequency based measures of helping behavior during breeding in mammals, we found support for all predictions flowing from the energetic framework of brain size evolution. Our first prediction was that energy subsidies from non-mothers allow species to evolve larger brains relative to other species where mothers bear the burden of raising offspring alone (prediction 1). Controlling for body size and the effects of phylogenetic relatedness, as well as for some possibly confounding variables, our analyses supported this prediction. The effect of help on fertility, on the other hand, was complementary to the effect on brain size, and was found mainly in the order of Primates.

The amount of phylogenetic structure in the data was high (lambda values mostly close to one), necessitating the application of phylogenetic methods. However, if trends within groups do not match the larger pattern found between clades, due to grade shifts that result from differences in lifestyle, phylogenetic models yield different results than analyses of species-level data (e.g., the effect of allonursing on brain size in Carnivora is significantly positive for

Table 2

Principal components analysis of helping behaviors within large orders.

\begin{tabular}{|c|c|c|c|c|c|c|c|c|c|c|c|}
\hline \multirow{3}{*}{ Group } & & \multirow{3}{*}{ Label } & \multirow{3}{*}{ Eigenvalue } & \multirow{3}{*}{ \% Var. expl. } & \multicolumn{7}{|c|}{ Rotated factor loadings } \\
\hline & & & & & \multirow[t]{2}{*}{ Allonursing } & \multirow[t]{2}{*}{ Comm. nesting/babysit/retrieval } & \multirow[t]{2}{*}{ Protect } & \multicolumn{2}{|c|}{ Provision } & \multicolumn{2}{|c|}{ Carry } \\
\hline & & & & & & & & Male & Others & Male & Others \\
\hline \multirow[t]{2}{*}{ Carnivora } & PC1 & Allocare & 3.318 & 66.4 & 0.102 & 0.827 & 0.952 & 0.899 & 0.615 & & \\
\hline & PC2 & Allonursing & 0.931 & 18.6 & 0.964 & 0.307 & 0.131 & 0.140 & 0.633 & & \\
\hline \multirow[t]{2}{*}{ Rodentia } & PC1 & Provision & 2.175 & 43.5 & -0.157 & 0.148 & 0.230 & 0.953 & 0.955 & & \\
\hline & PC2 & Allocare & 1.462 & 29.2 & 0.528 & 0.865 & 0.825 & 0.099 & 0.013 & & \\
\hline \multirow[t]{2}{*}{ Primates } & PC1 & Allocare & 3.868 & 55.3 & 0.034 & 0.729 & 0.613 & 0.938 & 0.891 & 0.828 & 0.749 \\
\hline & PC2 & Allonursing & 1.153 & 16.5 & 0.888 & -0.236 & -0.419 & -0.015 & 0.158 & -0.291 & 0.252 \\
\hline \multirow[t]{2}{*}{ Artiodactyla } & PC1 & Allocare & 1.511 & 50.4 & 0.865 & 0.871 & -0.017 & & & & \\
\hline & PC2 & Protect & 1.005 & 33.5 & -0.109 & 0.076 & 0.996 & & & & \\
\hline
\end{tabular}

Factor loadings $>0.5$ are shown in bold face. 
Table 3

Phylogenetic multivariate regression models (PGLS) of the components of help on brain size, A) in mammals (on the level of suborders), B) in mammals (species-level), and C) within large orders.

\begin{tabular}{|c|c|c|c|c|c|c|c|c|c|c|c|}
\hline \multirow[t]{2}{*}{ Brain size } & \multirow[t]{2}{*}{$N$} & \multirow[t]{2}{*}{ Lambda } & \multirow[t]{2}{*}{$\operatorname{adj} R^{2}$} & \multirow[t]{2}{*}{ AICc } & \multicolumn{2}{|c|}{$\begin{array}{l}p \text {-values of Help } \\
\text { factors from PCA }\end{array}$} & \multicolumn{5}{|c|}{$p$-values of Covariates } \\
\hline & & & & & PC1 & PC2 & Gregariousness & Diet & Activity & Substrate & Body mass \\
\hline \multicolumn{12}{|l|}{ A) } \\
\hline Suborders & 28 & $0.000^{* *}$ & 0.973 & 39.7 & $0.023+$ & $0.775+$ & $0.873+$ & $0.176-$ & $0.800+$ & $0.212+$ & $<0.0001+$ \\
\hline \multicolumn{12}{|l|}{ B) } \\
\hline All mammals & 445 & $0.978^{* * *}$ & 0.903 & -123.1 & $0.397+$ & $0.111+$ & $0.497+$ & $0.002-$ & $0.788+$ & $0.117+$ & $<0.001+$ \\
\hline \multicolumn{12}{|l|}{ C) } \\
\hline Carnivora & 101 & $0.953^{* * *}$ & 0.931 & -53.9 & $0.001+$ & $0.025+$ & $0.104-$ & $0.146-$ & $0.548+$ & $0.320+$ & $<0.001+$ \\
\hline Rodentia & 113 & $0.915^{* * *}$ & 0.937 & -58.9 & $0.018+$ & $0.087+$ & 0.739 & $0.076-$ & $0.878+$ & $0.026+$ & $<0.001+$ \\
\hline Primates & 98 & $0.989 * * *$ & 0.888 & -79.5 & $0.010-$ & $0.037+$ & $0.251+$ & $0.231-$ & $0.746+$ & $0.432-$ & $<0.001+$ \\
\hline Artiodactyla & 66 & $0.995^{*}$ & 0.903 & -15.9 & $0.185+$ & $0.873-$ & $0.088+$ & $0.411+$ & $0.395-$ & & $<0.001+$ \\
\hline
\end{tabular}

Note that in C), the nature of help summarized by PC1 and PC2 differs for the various orders, see Table 2. For help factors and covariates, the table lists $p$-values followed by the direction of the effect ( + or - ). Lambda values are estimated by Maximum Likelihood, the number of asterisks indicates significant differences from 0 or $1(* * *$ : significantly different from both 0 and $1,{ }^{* *}$ : significantly different from $1,{ }^{*}$ : significantly different from 0 ). Significant $p$-values are shown in bold face.

PGLS, but not for raw species analyses). In this case, results of phylogenetic analyses are more reliable.

In some of our analyses, however, trends within different clades were completely opposite, as in the relationship between allocare (PC1) and brain size in primates versus carnivores. In such cases, phylogenetic regression on the species-level is not appropriate to find the prevailing trend in mammals as a group, as the more speciose clade will determine the overall trend, or, as in our case of two clades of equal sample size, the opposing trends will cancel each other. Therefore, we also analyzed mammals on the suborder level, which gives appropriate weight also to suborders with only a few or single members. Lambda was zero in this sample, indicating that taking suborder means effectively corrected for phylogenetic dependence. At that level, we found a significantly positive correlation between allomaternal care (PC1) and brain size also in mammals as a whole (cf. Fig. 2).

The inclusion of potentially confounding variables, on the other hand, had very limited effects on the correlations between help and brain size or fertility. Nevertheless, it was important to include a rough measure of gregariousness in order to exclude the possibility that the observed effects are rather due to a social lifestyle than due to energetic effects of allomaternal care. When we excluded these confounding variables from the analyses, none of our conclusions changed.

The second prediction, that direct forms of help were more effective than indirect forms, was also supported by our results, although the details of which behaviors clustered together varied according to lifestyle. Provisioning and carrying were highly correlated with brain size or fertility. Allonursing was too, to a slightly lesser extent, whereas babysitting, retrieval and huddling, or protection, have a much weaker effect if they are not coupled to the direct forms of help. Interestingly, the three species of rodents that exhibit provisioning (Castor canadensis, Onychomys leucogaster, and Octodon degus) are very distantly related to each other, but all three have considerably larger brains than their relatives, strongly supporting the idea that energy inputs allowed brains to increase in size. Grasshopper mice, Onychomys, are the only true carnivores among rodents (Egoscue, 1960) and are renowned for being violently aggressive toward conspecifics other than their mates (Ruffer, 1968). Whereas male O. leucogaster are reported to provision their offspring (Ruffer, 1965; Burt and Grossenheider, 1976), males of its smaller-brained sister species Onychomys torridus only huddle and groom (McCarty and Southwick, 1977). These three contrasts are largely responsible for the positive correlation between brain size and provisioning in rodents, and further, more detailed studies of them or other, hitherto unknown species of rodents exhibiting provisioning would be needed to corroborate this result.

Artiodactyla, on the other hand, never provision their offspring, and our results suggest that protection and babysitting do not have enough of an energetic benefit to exert an effect on fertility or brain size in this group. However, elephants exhibit a considerable amount of allomaternal care (mainly by other adult females, Lee, 1987), and they have relatively larger brains than hoofed

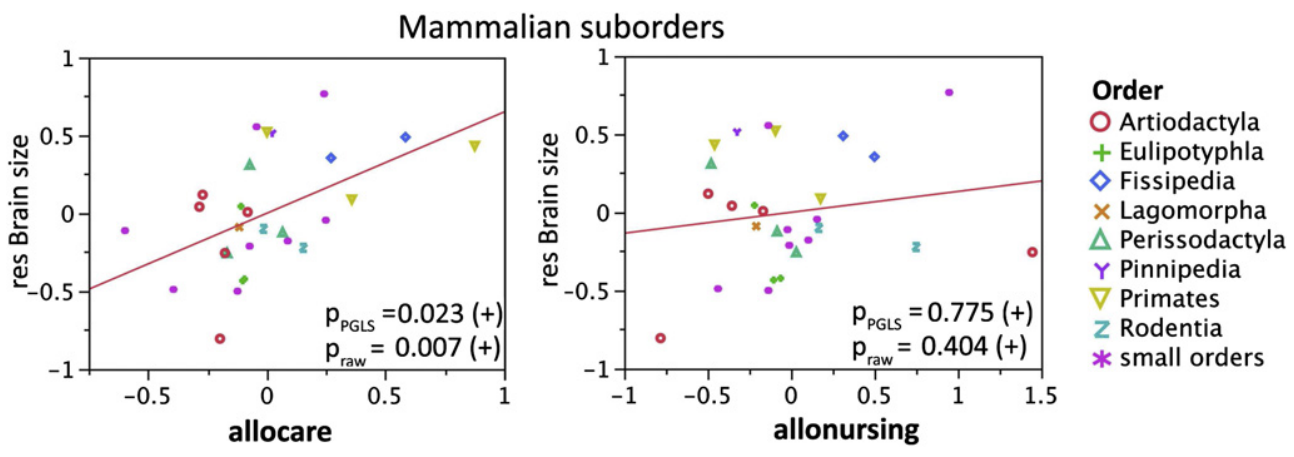

Figure 2. Correlations between brain size and factors of allomaternal help in mammals at the level of suborders. Factors of help are the first two rotated components of the nonphylogenetic principal components analyses (cf. Table 1). The mean residuals of brain size (and mean help factors, respectively) are the mean residuals for all species in the suborder, derived from multiple least-squares models including body mass, diet, substrate use, and activity. $p$-Values ( $p_{\text {raw }}$ ) of least-squares regressions between these residuals are shown, with the direction of the effect shown in parentheses. Details of phylogenetic models are shown in Table $3 \mathrm{~A}$, and the $p$-values ( $p_{\mathrm{PGLS}}$ ) are noted on the graphs. 


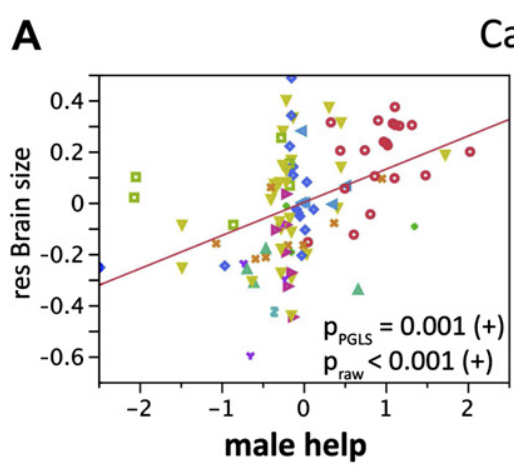

\section{Carnivora}

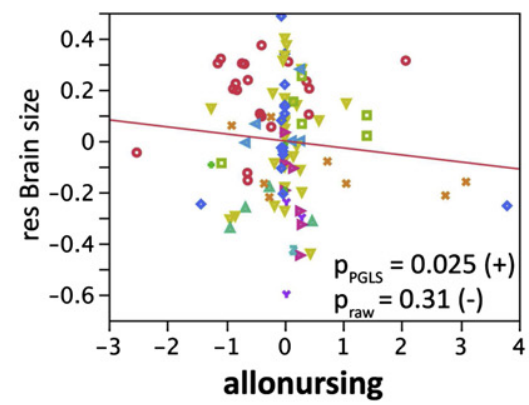

Rodentia
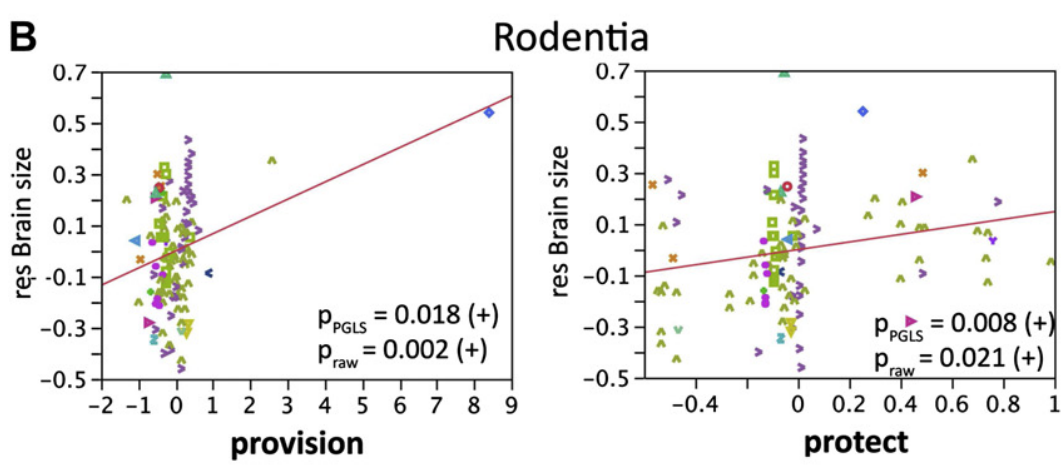

Family

O Canidae

+ Eupleridae

$\diamond$ Felidae

$\times$ Herpestidae

$\triangle$ Hyaenidae

Y Mephitidae

$\nabla$ Mustelidae

Z Nandiniidae

* Prionodontidae

$\square$ Procyonidae

$\triangleleft$ Ursidae

$\triangleright$ Viverridae

Family

O Agoutidae

+ Bathyergidae

$\diamond$ Castoridae

$\times$ Caviidae

$\triangle$ Chinchillidae

Y Dasyproctidae

$\nabla$ Dipodidae

$z$ Erethizontidae

* Geomyidae

$\square$ Heteromyidae

$\triangleleft$ Hydrochaeridae

$\triangleright$ Hystricidae

$\wedge$ Muridae

$\checkmark$ Myoxidae

< Octodontidae

$>$ Sciuridae

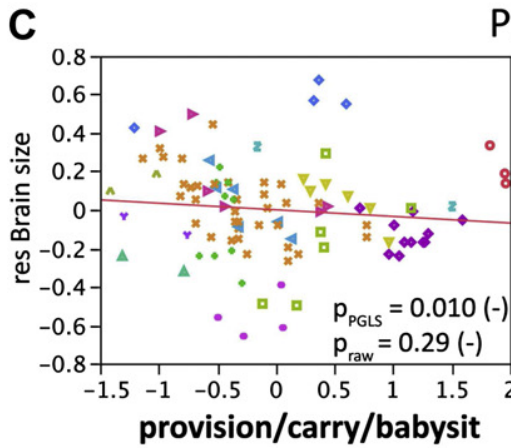

Primates

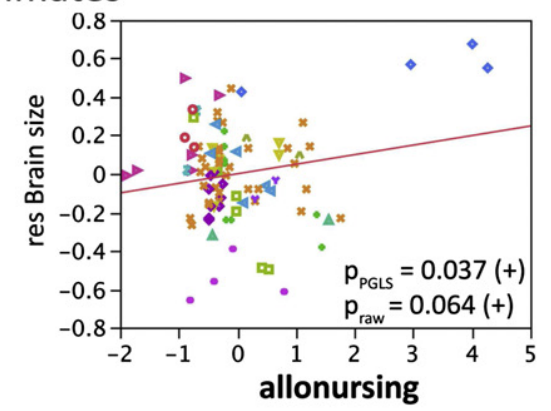

Family

O Aotidae

+ Atelidae

$\diamond$ Cebidae

$\diamond$ Callitrichinae

$\times$ Cercopithecidae

$\triangle$ Cheirogaleidae

Y Galagidae

$\nabla$ Hominidae

z Hylobatidae

* Indriidae

$\square$ Lemuridae

$\checkmark$ Lorisidae

$\triangleright$ Pitheciidae

D

Artiodactyla
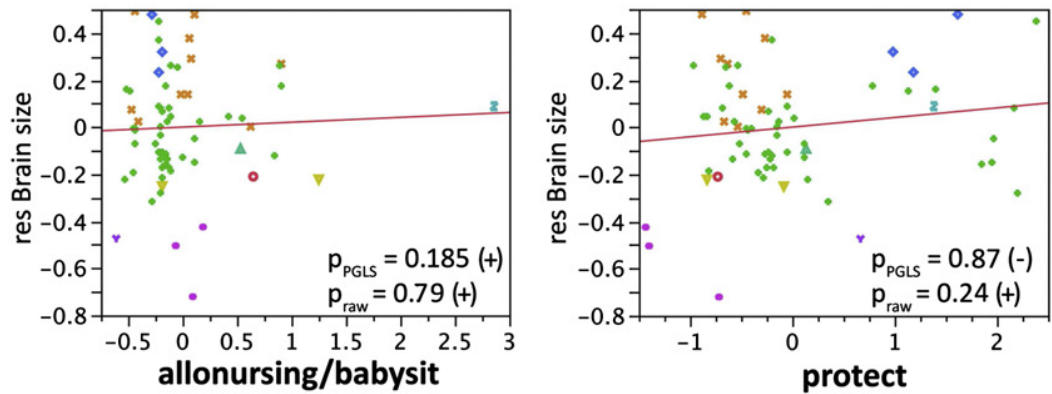

Family

Antilocapridae

+ Bovidae

$\diamond$ Camelidae

$\times$ Cervidae

$\triangle$ Giraffidae

Y Hippopotamidae

$\nabla$ Suidae

z Tayassuidae

* Tragulidae

Figure 3. Correlations between brain size and factors of allomaternal help in large mammalian orders. A) fissiped Carnivora, B) Rodentia, C) Primates, and D) Artiodactyla. Factors of help are the first two rotated components of the non-phylogenetic principal components analyses (cf. Table 2). For Rodentia, the first factor of non-phylogenetic ('provision') and the second factor of phylogenetic PCA ('protect', cf. Table S2) are shown (see text for an explanation). The mean residuals of brain size (and help factors, respectively) are the mean residuals for all species derived from multiple least-squares models including body mass, diet, substrate use, and activity. $p$-Values ( $p_{\text {raw }}$ ) of least-squares regressions between these

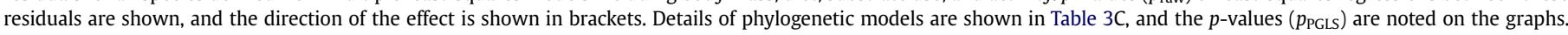

mammals (cf. Fig. 2), to which they may best be compared due to their lifestyle and diet, although they are not directly related.

For Carnivora, our findings are directly opposite to the pattern found by Gittleman (1994), in that singly breeding carnivore mothers have relatively smaller brains than species with some allomaternal care. Most noteworthy, brain size data are almost identical in the two studies, as the measurements of Gittleman (1994) still provide the most comprehensive and reliable 
Table 4

Phylogenetic multivariate regression models (PGLS) of the components of help on fertility, A) in mammals (on the level of suborders), B) in mammals (species-level), and C) within large orders.

\begin{tabular}{|c|c|c|c|c|c|c|c|c|c|c|c|}
\hline \multirow[t]{2}{*}{ Fertility } & \multirow[t]{2}{*}{$N$} & \multirow[t]{2}{*}{ Lambda } & \multirow[t]{2}{*}{$\operatorname{adj} R^{2}$} & \multirow[t]{2}{*}{ AICc } & \multicolumn{2}{|c|}{$\begin{array}{l}p \text {-values of Covariates } \\
\text { Help factors from PCA }\end{array}$} & \multicolumn{5}{|c|}{$p$-values of Covariates } \\
\hline & & & & & PC1 & PC2 & Gregariousness & Diet & Activity & Substrate & Body mass \\
\hline \multicolumn{12}{|l|}{ A) } \\
\hline Suborders & 28 & $0.000 * *$ & 0.710 & 63.9 & $0.183-$ & $0.034+$ & $0.749-$ & $0.679+$ & $0.811+$ & $0.331-$ & $<0.001-$ \\
\hline \multicolumn{12}{|l|}{ B) } \\
\hline All mammals & 406 & $0.913^{* * *}$ & 0.213 & 523.4 & $0.013+$ & $0.282+$ & $0.351-$ & $0.211+$ & $0.127+$ & $0.285-$ & $<0.001-$ \\
\hline \multicolumn{12}{|l|}{ C) } \\
\hline Carnivora & 98 & $0.798^{* * *}$ & 0.179 & 134.8 & $0.779-$ & $0.076+$ & $0.923-$ & $0.967+$ & $0.522+$ & $0.506+$ & $<0.001-$ \\
\hline Rodentia & 99 & $0.889 * * *$ & 0.105 & 144.3 & $0.782-$ & $0.732+$ & $0.950-$ & 0.484 & $0.385+$ & $0.522-$ & $<0.001-$ \\
\hline Primates & 84 & $0.673 * *$ & 0.602 & 88.5 & $0.002+$ & $0.589-$ & $0.080+$ & $0.610_{-}$ & $0.867+$ & $0.098-$ & $<0.001-$ \\
\hline Artiodactyla & 60 & $0.895^{* * *}$ & 0.152 & 63.0 & $0.196+$ & $0.381-$ & $0.161-$ & $0.278+$ & $0.065+$ & & $<0.001-$ \\
\hline
\end{tabular}

Note that in C), the nature of help summarized by PC1 and PC2 differs for the various orders, see Table 2. For lambda values, see legend of Table 3. Significant $p$-values are shown in bold face.

database of carnivore brain sizes. Therefore, the discrepancy may be partly attributed to the new data on social behavior that has been published in the last 15 years, and partly to the doubling of sample size ( $N=101$ versus $N=50$ terrestrial carnivores).

Turning now to the predictions that concern the development stage at birth, we predicted that precocial species with allomaternal help show a shift of their development mode toward the altricial end of the spectrum, if this can be done without increasing the predation risk of the now more altricial offspring (prediction 3). In primates, we did indeed find a pronounced shift toward altriciality in species that provide more help, especially within New World monkeys. In most ungulates and elephants, predation risk of insufficiently precocial neonates prevents a shift toward altriciality. This option is only available if offspring are efficiently protected and defended within a nest, as in some species of Suidae, which have both relatively altricial offspring and communal care (e.g., peccaries). However, due to the rarity of this adaptation it was not detected in our phylogenetic analyses. On the other hand, we found a shift toward more precocial offspring with increased protection by males in Artiodactyla, and in rodents with more provisioning. In these groups, help thus seems to allow for a (gradual) change in life history toward the production of more precocial offspring with better chances of survival to adulthood (prediction 4), but this result is in need of corroboration by comparing juvenile survival rates.

Load reduction of mothers by a shortening of the strenuous lactation period (see SOM for evidence that the relative energetic load during gestation is lower than during lactation), exists in primates, and as a trend also in carnivores. Rodents, on the other hand, show an increase in the duration of the lactation period with indirect forms of help such as huddling, retrieval and protection. Again, more help tends to increase a quality-over-quantity strategy

Table 5

Phylogenetic multivariate regression models (PGLS) of the components of help on gestation length, lactation length, age at first reproduction (AFR) and maximum lifespan.

\begin{tabular}{|c|c|c|c|c|c|c|c|c|c|c|c|c|}
\hline \multirow{2}{*}{$\begin{array}{c}\text { Life history } \\
\text { Group }\end{array}$} & \multirow[t]{2}{*}{ LH trait } & \multirow[t]{2}{*}{$N$} & \multirow[t]{2}{*}{ Lambda } & \multirow[t]{2}{*}{$\operatorname{adj} R^{2}$} & \multirow[t]{2}{*}{ AICc } & \multicolumn{2}{|c|}{$\begin{array}{l}p \text {-values of Help } \\
\text { factors from PCA }\end{array}$} & \multicolumn{5}{|c|}{$p$-values of Covariates } \\
\hline & & & & & & PC1 & PC2 & Gregariousness & Diet & Activity & Substrate & Body mass \\
\hline Suborders & $\begin{array}{l}\text { Gestation } \\
\text { Lactation } \\
\text { AFR } \\
\text { Max lifespan }\end{array}$ & $\begin{array}{l}28 \\
27 \\
28 \\
27\end{array}$ & $\begin{array}{l}0.000^{* *} \\
0.000 \\
1.000 \\
0.000\end{array}$ & $\begin{array}{l}0.271 \\
0.083 \\
0.366 \\
0.204\end{array}$ & $\begin{array}{l}78.5 \\
87.5 \\
82.3 \\
69.3\end{array}$ & $\begin{array}{l}0.987- \\
0.723- \\
0.105- \\
0.845-\end{array}$ & $\begin{array}{l}0.390- \\
0.437- \\
0.861- \\
0.505-\end{array}$ & $\begin{array}{l}0.344- \\
0.330- \\
0.143- \\
0.161-\end{array}$ & $\begin{array}{l}\mathbf{0 . 0 1 7}- \\
0.081- \\
\mathbf{0 . 0 1 6}- \\
0.087-\end{array}$ & $\begin{array}{l}0.072- \\
0.373- \\
0.585- \\
0.155-\end{array}$ & $\begin{array}{l}0.099+ \\
0.141+ \\
0.042+ \\
0.123+\end{array}$ & $\begin{array}{l}0.009+ \\
0.052+ \\
0.008+ \\
0.016+\end{array}$ \\
\hline All mammals & $\begin{array}{l}\text { Gestation } \\
\text { Lactation } \\
\text { AFR } \\
\text { Max lifespan }\end{array}$ & $\begin{array}{l}416 \\
418 \\
427 \\
394\end{array}$ & $\begin{array}{l}0.995^{*} \\
0.605^{* * * *} \\
0.693^{* * *} \\
0.230^{* * *}\end{array}$ & $\begin{array}{l}0.250 \\
0.088 \\
0.179 \\
0.171\end{array}$ & $\begin{array}{r}-150.4 \\
1289.1 \\
840.1 \\
972.7\end{array}$ & $\begin{array}{l}0.560+ \\
0.432- \\
0.338+ \\
\mathbf{0 . 0 4 0 +}\end{array}$ & $\begin{array}{l}0.692+ \\
0.074+ \\
0.673- \\
0.143+\end{array}$ & $\begin{array}{l}0.384+ \\
0.903+ \\
0.511- \\
0.827+\end{array}$ & $\begin{array}{l}\mathbf{0 . 0 4 4 -} \\
0.090- \\
0.441- \\
\mathbf{0 . 0 4 6 -}\end{array}$ & $\begin{array}{l}0.631+ \\
0.309+ \\
0.321+ \\
0.079-\end{array}$ & $\begin{array}{c}0.680+ \\
0.186- \\
0.138+ \\
\mathbf{0 . 0 0 0 1 +}\end{array}$ & $\begin{array}{l}<0.001+ \\
<0.0001+ \\
<0.0001+ \\
<0.0001+\end{array}$ \\
\hline Carnivora & $\begin{array}{l}\text { Gestation } \\
\text { Lactation } \\
\text { AFR } \\
\text { Max lifespan }\end{array}$ & $\begin{array}{l}97 \\
90 \\
91 \\
93\end{array}$ & $\begin{array}{l}0.971^{*} \\
0.863^{* * *} \\
0.719^{* * *} \\
1.000^{*}\end{array}$ & $\begin{array}{l}0.170 \\
0.386 \\
0.437 \\
0.268\end{array}$ & $\begin{array}{r}-26.3 \\
94.6 \\
88.8 \\
-0.3\end{array}$ & $\begin{array}{l}0.588- \\
0.083- \\
0.926- \\
0.418+\end{array}$ & $\begin{array}{l}0.971+ \\
0.147- \\
0.875+ \\
0.395+\end{array}$ & $\begin{array}{l}0.268+ \\
\mathbf{0 . 0 4 1}+ \\
0.477+ \\
0.636+\end{array}$ & $\begin{array}{l}0.224- \\
0.537+ \\
0.362+ \\
\mathbf{0 . 0 0 9 -}\end{array}$ & $\begin{array}{l}0.141+ \\
0.601+ \\
0.605+ \\
0.105+\end{array}$ & $\begin{array}{l}0.932+ \\
0.796+ \\
0.905- \\
0.051+\end{array}$ & $\begin{array}{l}<0.0001+ \\
<0.0001+ \\
<0.0001+ \\
<0.0001+\end{array}$ \\
\hline Rodentia & $\begin{array}{l}\text { Gestation } \\
\text { Lactation } \\
\text { AFR } \\
\text { Max lifespan }\end{array}$ & $\begin{array}{r}105 \\
103 \\
103 \\
94\end{array}$ & $\begin{array}{l}1.000^{*} \\
0.840^{* * *} \\
0.675^{* * *} \\
0.784^{* * *}\end{array}$ & $\begin{array}{l}0.247 \\
0.239 \\
0.304 \\
0.236\end{array}$ & $\begin{array}{r}-51.5 \\
29.9 \\
173.0 \\
107.4\end{array}$ & $\begin{array}{l}\mathbf{0 . 0 0 5 +} \\
0.460+ \\
0.323+ \\
0.084+\end{array}$ & $\begin{array}{l}0.094+ \\
\mathbf{0 . 0 0 3 +} \\
0.572- \\
0.308+\end{array}$ & $\begin{array}{l}0.408- \\
0.056- \\
0.695- \\
0.595+\end{array}$ & $\begin{array}{l}0.987+ \\
0.259- \\
0.840- \\
0.609-\end{array}$ & $\begin{array}{l}0.323- \\
\mathbf{0 . 0 3 6}+ \\
0.515+ \\
0.046-\end{array}$ & $\begin{array}{l}0.326+ \\
\mathbf{0 . 0 4 0 +} \\
0.286+ \\
0.072+\end{array}$ & $\begin{array}{l}<0.0001+ \\
<0.0001+ \\
<0.0001+ \\
<0.0001+\end{array}$ \\
\hline Primates & $\begin{array}{l}\text { Gestation } \\
\text { Lactation } \\
\text { AFR } \\
\text { Max lifespan }\end{array}$ & $\begin{array}{l}84 \\
85 \\
84 \\
87\end{array}$ & $\begin{array}{l}0.982^{* * *} \\
0.794^{* * *} \\
1.000^{*} \\
0.821^{* *}\end{array}$ & $\begin{array}{l}0.272 \\
0.634 \\
0.076 \\
0.344\end{array}$ & $\begin{array}{r}-112.6 \\
82.8 \\
52.0 \\
-23.6\end{array}$ & $\begin{array}{l}\mathbf{0 . 0 3 7}- \\
\mathbf{0 . 0 1 7}- \\
0.462- \\
0.803-\end{array}$ & $\begin{array}{l}0.642- \\
0.072+ \\
0.549+ \\
\mathbf{0 . 0 3 4 +}\end{array}$ & $\begin{array}{l}0.928+ \\
0.611- \\
0.984+ \\
0.862-\end{array}$ & $\begin{array}{l}0.411+ \\
0.293+ \\
0.641+ \\
0.594-\end{array}$ & $\begin{array}{l}0.138+ \\
0.610+ \\
0.571+ \\
0.727-\end{array}$ & $\begin{array}{l}0.915- \\
0.197+ \\
0.763+ \\
0.344+\end{array}$ & $\begin{array}{l}0.001+ \\
<0.0001+ \\
0.007+ \\
<0.0001+\end{array}$ \\
\hline Artiodactyla & $\begin{array}{l}\text { Gestation } \\
\text { Lactation } \\
\text { AFR } \\
\text { Max lifespan }\end{array}$ & $\begin{array}{l}65 \\
52 \\
60 \\
64\end{array}$ & $\begin{array}{l}1.000^{*} \\
0.573^{* *} \\
0.000^{* *} \\
0.729\end{array}$ & $\begin{array}{l}0.410 \\
0.506 \\
0.597 \\
0.386\end{array}$ & $\begin{array}{r}-55.3 \\
45.6 \\
57.9 \\
-12.6\end{array}$ & $\begin{array}{l}0.890+ \\
0.231- \\
0.598- \\
0.112+\end{array}$ & $\begin{array}{l}\mathbf{0 . 0 0 0 3 +} \\
0.484+ \\
0.707+ \\
0.774+\end{array}$ & $\begin{array}{l}0.844+ \\
0.810+ \\
\mathbf{0 . 0 1 0}+ \\
0.161+\end{array}$ & $\begin{array}{l}0.327- \\
0.255+ \\
0.053- \\
0.545-\end{array}$ & $\begin{array}{l}0.588+ \\
0.231+ \\
0.909+ \\
0.282-\end{array}$ & & $\begin{array}{l}<0.0001+ \\
<0.0001+ \\
<0.0001+ \\
<0.0001+\end{array}$ \\
\hline
\end{tabular}

Note that PC1 and PC2 differ according to the analyzed group, see Table 2. For lambda values, see legend of Table 3. Significant $p$-values are shown in bold face. 
Table 6

Phylogenetic multivariate regression models (PGLS) of the components of help and provisioning of mothers on brain size, fertility, gestation length, lactation length, age at first reproduction (AFR) and maximum lifespan, in Carnivora.

\begin{tabular}{|c|c|c|c|c|c|c|c|c|c|c|}
\hline \multirow[t]{2}{*}{ Carnivora } & \multirow[t]{2}{*}{$N$} & \multirow[t]{2}{*}{ Lambda } & \multirow[t]{2}{*}{$\operatorname{adj} R^{2}$} & \multicolumn{3}{|c|}{$p$-Values of help factors } & \multicolumn{4}{|c|}{$p$-Values of covariates } \\
\hline & & & & PC1 & PC2 & Provision of mothers & Gregariousness & Diet & Activity & Body mass \\
\hline Brain size & 27 & $0.000 * *$ & 0.978 & $0.087+$ & $0.363+$ & $0.022+$ & $0.522-$ & $0.112-$ & $0.592+$ & $<0.0001+$ \\
\hline Fertility & 27 & $0.730^{* *}$ & 0.194 & $0.840-$ & $0.086+$ & $0.765+$ & $0.413-$ & $0.547+$ & $0.097+$ & $0.575-$ \\
\hline Gestation & 26 & 1.000 & 0.045 & $0.940-$ & $0.186-$ & $0.315-$ & $0.067+$ & $0.647-$ & $0.733-$ & $0.226+$ \\
\hline Lactation & 25 & $0.885^{*}$ & 0.465 & $0.053-$ & $0.016-$ & $0.751-$ & $0.007+$ & $0.785-$ & $0.181-$ & $0.065+$ \\
\hline AFR & 27 & $0.976^{*}$ & 0.596 & $0.504+$ & $0.313+$ & $0.399+$ & $0.871+$ & $0.025+$ & $0.101-$ & $0.013+$ \\
\hline Max. lifespan & 27 & $1.000^{*}$ & 0.305 & $0.336+$ & $0.606+$ & $0.366-$ & $0.331+$ & $0.079-$ & $0.239+$ & $0.019+$ \\
\hline \multicolumn{11}{|c|}{ Control: same sample without the variable 'provisioning of mothers' } \\
\hline Brain size & 27 & $0.000 * *$ & 0.972 & $0.0005+$ & $0.156+$ & & $0.225-$ & $0.034-$ & $0.223+$ & $<0.0001+$ \\
\hline
\end{tabular}

For lambda values, see legend of Table 3. Significant $p$-values are shown in bold face.

of offspring production in rodents. We did not observe any consistent correlations between allomaternal care and lifespan, perhaps because our data on maximum lifespan are not sex-specific.

In primates, the results of our PCA suggests that allonursing (occurring in $17 \%$ of the species and explaining $16 \%$ of the variation in helping behaviors) is not additive to other helping behaviors (i.e., just another element of helping, as suggested by e.g., the classification scheme of Hrdy (2010)), but rather an independent dimension of allomaternal care, which is probably more related to patterns of relatedness and tolerance among adult females. With respect to the correlation of help with brain size and fertility our results confirm earlier studies (Mitani and Watts, 1997; Ross and MacLarnon, 2000); help mainly increases fertility, as the high energetic load of carrying the offspring and lactating at the same time is alleviated through cooperative care. However, this strategy is most pronounced in New World monkeys. Callitrichid primates regularly produce twins, and the father and other group members carry them shortly after birth for most of the time (Digby et al., 2007). Here, the increased fertility has an interesting consequence. During gestation, the mother has to bear the energetic load of production alone. This burden is partly reduced by shortening gestation length, and giving birth to more altricial offspring with relatively smaller brains at birth (DeSilva and Lesnik, 2008, their figure 6), even if their small adult brains are taken into account. But nevertheless, in species that evolved twinning the energetic load during gestation became so large (e.g., Nievergelt and Martin, 1999) that relative brain size was reduced, even relative to ancestral values in the callithrichid lineage (Montgomery et al., 2010). On the other hand, we found that allonursing is positively correlated with brain size in primates. However, rather than a weak energetic effect this may also reflect a higher level of tolerance in those species that exhibit allonursing, which facilitates social learning from conspecifics other than the mother and may thus increase the effectiveness of transferring enhanced cognitive abilities.

In sum, we found support for an energetic effect of help on brain size: an additional influx of energy into the mother-offspring unit, as provided e.g., by help of the male or non-breeding group members, is significantly correlated with brain size, but not with fertility, in most taxa groups and for most factors of help. The one notable exception are the nonhuman primates, especially the Neotropical platyrrhines, where a strong negative effect of cooperative care on brain size is paired with a strong positive effect on fertility and altriciality of the offspring.

\section{Allomaternal care and human evolution}

How do humans fit into this picture? We will argue that the help, especially the provisioning, received by human mothers partly explain our increased brain size relative to the ancestral state and that the finding for primates, of help producing higher reproductive rates and more altricial young, also holds in humans.

Humans are cooperative breeders. Group members of both sexes and including both reproductive men and non-reproductive group members, such as post-reproductive kinswomen (cf. Hawkes et al., 1998) and older siblings, help mothers in the form of food provisioning, carrying, protecting and babysitting the infants (reviewed in Hrdy, 2009). Indeed, among foragers mothers are provided with more food (about $3500 \mathrm{~kJ}$ per day, Kaplan et al., 2000) during both gestation and lactation than they actually need to cover the maximum additional costs of gestation or lactation (Butte and King, 2005; Sellen, 2007). Provisioning the children with mashed or cooked food that is both easy to chew and digest begins even before weaning and provisioning with solid food continues for years afterward (Bogin, 1998).

At the same time, humans are 'secondarily altricial' (Portmann, 1962 ) in so far as their brains are relatively immature at birth. In modern humans, the brain has attained only $28.0 \%$ of adult size at birth compared with $40.1 \%$ in chimpanzees (DeSilva and Lesnik, 2006) and our neonates are somewhat more helpless than those of our closest relatives, the great apes (Schultz, 1949). Nonetheless, thermoregulatory ability and a high metabolic rate are already achieved by a few hours after birth, as in precocial mammals, even if a reversion to hypoxic hypometabolism is still possible for a few days after birth (Singer and Mühlfeld, 2007). The prevalent explanation for this more altricial state of the human neonate is that the narrowing of the pelvic canal as a result of bipedality has at one point in our evolutionary history become limiting for neonate head size (the 'obstetrical dilemma'; see Washburn, 1960; Montagu, 1961; Trevathan, 1987). However, there is considerable debate about the time of origin (cf. DeSilva, 2011) and even the existence (S. Pfeiffer, Personal communication) of such a constraint. We argue that the increased efficiency of postnatal allomaternal care provides an alternative explanation for the relatively altricial state of human neonates at birth, which simultaneously explains other peculiarities of human developmental timing such as early weaning and shortened interbirth intervals. However, current data on fossils do not allow us to determine when these changes did occur, as neither tooth eruption patterns nor dental attrition in infants (Aiello et al., 1991) are conclusive in this respect (e.g., Skinner and Wood, 2006; Dean, 2010). The most promising approach to detect the age at weaning in fossils seems to be to look for changes in the stable isotope composition of enamel (see Humphrey, 2010; Eerkens et al., 2011).

Overall, humans not only deviate from the primate trend through extensive provisioning of infants with high-quality food, but also through the provisioning of mothers and weaned offspring. In this respect, humans resemble Carnivora, where we found that 
provisioning of mothers yields an additional positive effect on brain size. Provisioning of mothers increases the upper limit of maternal energy expenditure during gestation and lactation, and therefore allows for indirectly shunting energy toward the offspring's brain development. Provisioning of weaned offspring is likely to allow for earlier weaning, in line with our finding of a negative correlation between help and age at weaning in primates (and a trend in carnivores). However, it would be necessary to obtain more detailed data on brain development in cooperatively breeding carnivores to be able to see whether post-weaning provisioning can still affect brain growth, or whether it instead facilitates the survival of a large-brained offspring, which is most vulnerable due to the mismatch between the already fully grown brain and its relatively small body. However, these energetic effects need not be found on a proximate level, as a direct mechanism. Thus, both experimental and comparative studies will be needed to investigate these effects, and gain further insight into human brain and life history evolution.

We do not argue that the approximately three-fold increase in brain size since the origin of the genus Homo is due entirely to help. Recently, we listed potential factors that may have played a role in human brain size increase in the Pleistocene (Navarrete et al., 2011). Building on earlier ideas (Martin, 1983, 1996; Aiello and Key, 2002; Aiello and Wells, 2002; Leonard et al., 2003), we showed which of these factors are supported by general relationships that are also found in other mammalian lineages, and argued that special pleading for humans is not needed. These factors include the stabilization of energy intake on a higher level through a change in diet and cognitive and physiological buffering of seasonality effects (van Woerden et al., 2010, 2012) as well as a reduction of energy spent on locomotion through abandonment of climbing and a more efficient bipedalism (Pontzer et al., 2010). The present study suggests that energy subsidies for mothers and infants play a major role in the stabilization of energy intake.

These various changes are related. Indeed, we argue that a change in lifestyle toward cooperative care could have been the first step toward encephalization, as the adaptation of cooperative breeding itself is clearly not dependent on high cognitive abilities (e.g., mole-rats, callitrichids, meerkats). However, because it was combined with an already ape-like cognition, cooperative breeding in early Homo may have had unprecedented consequences. In our scenario, social tolerance increased, opportunities for social learning of ecological skills arose more frequently (van Schaik and Burkart, 2011), and a skill-intensive niche, relying on tool-based processing of meat or marrow, was gradually occupied (or constructed, cf. Kaplan et al., 2000; Laland et al., 2000; Iriki, 2008). Shared intentionality and frequent food sharing between adults (Jaeggi and van Schaik, 2011) facilitated joint defense and thus exploitation of big game carcasses (e.g., Pobiner et al., 2008). Within a relatively short time, the innovation of cooperative hunting and perhaps cooking (cf. Carmody et al., 2011) spread among the cooperatively breeding early hominins, and the ensuing more stable supply of high-quality food allowed for a further increase in both fertility and brain size. At one point, care for sick or injured group members also reduced adult mortality, which allowed humans to gradually evolve a longer lifespan (cf. the find of an old toothless individual in Dmanisi, 1.77 Ma BP (millions of years ago, before present), Rightmire et al., 2006). Studies of birds found that cooperative breeding is more frequent in open habitats such as savanna (Rubenstein and Lovette, 2007), and the first out-of-Africa event indicates that early Homo must have had relatively high reproductive rates.

We conclude that brain size increase in the hominin lineage was only feasible after substantial energetic inputs due to helping, and particularly provisioning of pregnant mothers, had evolved, signaling the origin of cooperative breeding in our lineage. But in addition to that, the psychological characteristics of a cooperatively breeding primate, in combination with an already rather large hominoid brain, produced the rapid and unparalleled brain expansion of modern humans (cf. Burkart et al., 2009; Burkart and van Schaik, 2010; van Schaik and Burkart, 2010).

\section{Acknowledgments}

We thank all the people who generously contributed data to our compilations, and Sarah B. Hrdy and an anonymous reviewer for helpful comments. Financial support was provided through Swiss National Science Foundation grant No. 3100A0-117789 and the A.H. Schultz foundation.

\section{Appendix A. Supplementary material}

Supplementary material associated with this article can be found, in the online version, at doi:10.1016/j.jhevol.2012.03.009.

\section{References}

Aiello, L.C., Key, C., 2002. Energetic consequences of being a Homo erectus female. Am. J. Hum. Biol. 14, 551-565.

Aiello, L.C., Wells, J.C.K., 2002. Energetics and the evolution of the genus Homo. Annu. Rev. Anthropol. 31, 323-338.

Aiello, L.C., Montgomery, C., Dean, C., 1991. The natural history of deciduous tooth attrition in hominoids. J. Hum. Evol. 21, 397-412.

Bales, K., Dietz, J.M., Baker, A.J., Miller, K.E., Tardif, S.D., 2000. Effects of allocaregivers on fitness of infants and parents in callitrichid primates. Folia Primatol. 71, 27-38.

Bernaards, C.A., Jennrich, R.J., 2005. Gradient projection algorithm and software for arbitrary rotation criteria in factor analysis. Educ. Psychol. Meas. 65, 676-696.

Bernard, R.T.F., Nurton, J., 1993. Ecological correlates of relative brain size in some South-African rodents. S. Afr. J. Zool. 28, 95-98.

Bininda-Emonds, O.R.P., Cardillo, M., Jones, K.E., MacPhee, R.D.E., Beck, R.M.D., Grenyer, R., Price, S.A., Vos, R.A., Gittleman, J.L., Purvis, A., 2007. The delayed rise of present-day mammals. Nature 446, 507-512.

Bogin, B., 1998. From caveman cuisine to fast food: the evolution of human nutrition. Growth Horm. IGF Res. 8, 79-86.

Bronson, F.H., 1989. Mammalian Reproductive Biology. Chicago University Press, Chicago.

Burkart, J.M., van Schaik, C.P., 2010. Cognitive consequences of cooperative breeding in primates? Anim. Cogn. 13, 1-19.

Burkart, J.M., Hrdy, S.B., van Schaik, C.P., 2009. Cooperative breeding and human cognitive evolution. Evol. Anthropol. 18, 175-186.

Burt, W., Grossenheider, R., 1976. Grasshopper mice. In: Peterson, R.A.E. (Ed.), The Peterson Field Guide Series: A Field Guide to the Mammals. Houghton Mifflin Company, Boston, pp. 166-167.

Butte, N.F., King, J.C., 2005. Energy requirements during pregnancy and lactation. Public Health Nutr. 8, 1010-1027.

Carmody, R.N., Weintraub, G.S., Wrangham, R.W., 2011. Energetic consequences of thermal and nonthermal food processing. Proc. Natl. Acad. Sci. 108, 19199-19203.

Charnov, E.L., 1993. Why do female primates have such long lifespans and so few babies? Or life in the slow lane. Evol. Anthropol. 1, 191-194.

Clutton-Brock, T.H., 1991. The Evolution of Parental Care. Princeton University Press, Princeton.

Dean, M.C., 2010. Retrieving chronological age from dental remains of early fossil hominins to reconstruct human growth in the past. Philos. Trans. R. Soc. B 365, 3397-3410.

DeSilva, J.M., 2011. A shift toward birthing relatively large infants early in human evolution. Proc. Natl. Acad. Sci. 108, 1022-1027.

DeSilva, J.M., Lesnik, J., 2006. Chimpanzee neonatal brain size: implications for brain growth in Homo erectus. J. Hum. Evol. 51, 207-212.

DeSilva, J.M., Lesnik, J.J., 2008. Brain size at birth throughout human evolution: a new method for estimating neonatal brain size in hominins. J. Hum. Evol. 55, 1064-1074.

Dewsbury, D.A., 1985. Paternal behavior in rodents. Am. Zool. 25, 841-852.

Digby, L.J., Ferrari, S.F., Saltzman, W., 2007. Callitrichines: the role of competition in cooperatively breeding species. In: Campbell, C.J., Fuentes, A., MacKinnon, K.C., Panger, M.A., Bearder, S.K. (Eds.), Primates in Perspective. Oxford University Press, New York, pp. 85-105.

Dobbing, J., Sands, J., 1979. Comparative aspects of the growth spurt. Early Hum. Dev. 3, 79-83.

Dunbar, R.I.M., 2009. The social brain hypothesis and its implications for social evolution. Ann. Hum. Biol. 36, 562-572. 
Eerkens, J.W., Berget, A.G., Bartelink, E.J., 2011. Estimating weaning and early childhood diet from serial micro-samples of dentin collagen. J. Archaeol. Sci. 38, 3101-3111.

Egoscue, H.J., 1960. Laboratory and field studies of the northern grasshopper mouse. J. Mammal. 41, 99-110.

Emlen, S.T., 1991. Evolution of Cooperative Breeding in Birds and Mammals. Blackwell Scientific Publications, Oxford.

Felsenstein, J., 1985. Phylogenies and the comparative method. Am. Nat. 125, 1-15.

Fish, J.L., Lockwood, C.A., 2003. Dietary constraints on encephalization in primates. Am. J. Phys. Anthropol. 120, 171-181.

Garber, P.A., Leigh, S.R., 1997. Ontogenetic variation in small-bodied New World primates: implications for patterns of reproduction and infant care. Folia Primatol. $68,1-22$.

Gittleman, J.L., 1986. Carnivore brain size, behavioral ecology, and phylogeny. J. Mammal. 67, 23-36.

Gittleman, J.L., 1994. Female brain size and parental care in carnivores. Proc. Natl. Acad. Sci. 91, 5495-5497.

Gittleman, J.L., Oftedal, O.T., 1987. Comparative growth and lactation in carnivores. Symp. Zool. Soc. Lond. 57, 41-77.

Groves, C.P., 2005. Order primates. In: Wilson, D.E., Reeder, D.M. (Eds.), Mamma Species of the World: A Taxonomic and Geographic Reference, third ed. Johns Hopkins University Press, Baltimore, pp. 111-184.

Gubernick, D.J., Klopfer, P.H., 1981. Parental Care in Mammals. Plenum Press, New York

Harvey, P.H., Bennett, P.M., 1983. Brain size, energetics, ecology and life-history patterns. Nature 306, 314-315.

Harvey, P.H., Purvis, A., 1999. Understanding the ecological and evolutionary reasons for life history variation: mammals as a case study. In: McGlade, J. (Ed.), Advanced Ecological Theory. Blackwell Science, Oxford pp. $232-247$

Harvey, P.H., Cluttonbrock, T.H., Mace, G.M., 1980. Brain size and ecology in small mammals and primates. Proc. Natl. Acad. Sci. 77, 4387-4389.

Hawkes, K., O'Connell, J.F., Blurton Jones, N.G., Alvarez, H., Charnov, E.L., 1998 Grandmothering, menopause, and the evolution of human life histories. Proc Natl. Acad. Sci. 95, 1336-1339.

Hayes, L.D., 2000. To nest communally or not to nest communally: a review of rodent communal nesting and nursing. Anim. Behav. 59, 677-688.

Hrdy, S.B., 2005. Evolutionary context of human development: the cooperative breeding model. In: Carter, C.S., Anhert, L., Grossmann, K.E., Hrdy, S.B. Lamb, M.E., Porges, S.W., Sachser, N. (Eds.), Attachment and Bonding: A New Synthesis. MIT Press, Cambridge, pp. 9-32.

Hrdy, S.B., 2009. Mothers and Others: The Evolutionary Origins of Mutual Understanding. Harvard University Press, Cambridge.

Hrdy, S.B., 2010. Estimating the Prevalence of Shared Care and Cooperative Breeding in the Order Primates, An Appendix to Mothers and Others: The Evolutionary Origins of Human Understanding (2009). http://www.citrona.com/hrdy/ documents/Appendixla.pdf (accessed 26.03.12).

Humphrey, L.T., 2010. Weaning behaviour in human evolution. Semin. Cell Dev. Biol. $21,453-461$.

Iriki, A., 2008. The neuroscience of primate intellectual evolution: natural selection and passive and intentional niche construction. Philos. Trans. R. Soc. B 363 2229-2241.

Isler, K., 2011. Energetic trade-offs between brain size and offspring production marsupials confirm a general mammalian pattern. Bioessays 33, 173-179.

Isler, K., van Schaik, C.P., 2009a. The expensive brain: a framework for explaining evolutionary changes in brain size. J. Hum. Evol. 57, 392-400.

Isler, K., van Schaik, C.P., 2009b. Why are there so few smart mammals (but so many smart birds)? Biol. Lett. 5, 125-129.

Iwaniuk, A.N., Arnold, K.E., 2004. Is cooperative breeding associated with bigge brains? A comparative test in the Corvida (Passeriformes). Ethology 110 203-220.

Jaeggi, A.V., van Schaik, C.P., 2011. The evolution of food sharing in primates. Behav. Ecol. Sociobiol. 65, 2125-2140.

Kaplan, H., Hill, K., Lancaster, J., Hurtado, A.M., 2000. A theory of human life history evolution: diet, intelligence, and longevity. Evol. Anthropol. 9, 156-185.

Kar, B.R., Rao, S.L., Chandramouli, B.A., 2008. Cognitive development in children with chronic protein energy malnutrition. Behav. Brain Funct. 4, 31.

Kirk, E.C., 2006. Visual influences on primate encephalization. J. Hum. Evol. 51, 76-90.

König, B., 1997. Cooperative care of young in mammals. Naturwissenschaften 84, 95-104.

König, B., 2006. Non-offspring nursing in mammals: general implication from a case study on house mice. In: Kappeler, P.M., van Schaik, C.P. (Eds.), Cooperation in Primates and Humans. Springer, Berlin, pp. 191-205.

Laland, K.N., Odling-Smee, J., Feldman, M.W., 2000. Niche construction, biological evolution, and cultural change. Behav. Brain Sci. 23, 131-146.

Lappan, S., 2009. The effects of lactation and infant care on adult energy budgets in wild siamangs (Symphalangus syndactylus). Am. J. Phys. Anthropol. 140, 290-301.

Lee, P.C., 1987. Allomothering among African elephants. Anim. Behav. 35, 278-291.

Leonard, W.R., Robertson, M.L., Snodgrass, J.J., Kuzawa, C.W., 2003. Metabolic correlates of hominid brain evolution. Comp. Biochem. Phys. A 136, 5-15.

Levitsky, D.A., Strupp, B.J., 1995. Malnutrition and the brain - changing concepts, changing concerns. J. Nutr. 125, S2212-S2220.
Mace, G.M., Harvey, P.H., Cluttonbrock, T.H., 1981. Brain size and ecology in small mammals. J. Zool. 193, 333-354.

Martin, R.D., 1983. Human brain evolution in an ecological context. In: Fifty-Second James Arthur Lecture on the Evolution of the Human Brain. American Museum of National History, New York.

Martin, R.D., 1996. Scaling of the mammalian brain: the maternal energy hypothesis. News Physiol. Sci. 11, 149-156.

McCarty, R., Southwick, C., 1977. Paternal care and the development of behavior in the southern grasshopper mouse, Onychomys torridus. Behav. Biol. 19, 476-490.

McNab, B.K., 2006. The energetics of reproduction in endotherms and its implication for their conservation. Integr. Comp. Biol. 46, 1159-1168.

Mink, J.W., Blumenschine, R.J., Adams, D.B., 1981. Ratio of central nervous system to body metabolism in vertebrates - its constancy and functional basis. Am. J. Physiol. 241, R203-R212.

Mitani, J.C., Watts, D., 1997. The evolution of non-maternal caretaking among anthropoid primates: do helpers help? Behav. Ecol. Sociobiol. 40, 213-220.

Moehlman, P.D., Hofer, H., 1997. Cooperative breeding, reproductive suppression, and body mass in canids. In: Solomon, N.G., French, J.A. (Eds.), Cooperative Breeding in Mammals. Cambridge University Press, Cambridge, pp. 76-127.

Montagu, A., 1961. Neonatal and infant maturity in man. J. Am. Med. Assoc. 178, 56-57.

Montgomery, S.H., Capellini, I., Barton, R.A., Mundy, N.I., 2010. Reconstructing the ups and downs of primate brain evolution: implications for adaptive hypotheses and Homo floresiensis. BMC Biol. 8, 9.

Myers, P., Espinosa, R., Parr, C.S., Jones, T., Hammond, G.S., Dewey, T.A., 2006. The Animal Diversity Web. University of Michigan, Ann Arbor. http:// animaldiversity.org (accessed 25.09.11).

Navarrete, A.F., van Schaik, C.P., Isler, K., 2011. Energetics and the evolution of human brain size. Nature 480, 91-93.

Nievergelt, C.M., Martin, R.D., 1999. Energy intake during reproduction in captive common marmosets (Callithrix jacchus). Physiol. Behav. 65, 849-854.

Nunn, C.L., 2011. The Comparative Approach in Evolutionary Anthropology and Biology. University of Chicago Press, Chicago.

Nunn, C.L., Barton, R.A., 2001. Comparative methods for studying primate adaptation and allometry. Evol. Anthropol. 10, 81-98.

Orme, D., Freckleton, R.P., Thomas, G., Petzoldt, T., Fritz, S.A., 2011. Caper Comparative Analyses of Phylogenetics and Evolution in R. http://r-forge.rproject.org/projects/caper.

Packer, C., Lewis, S., Pusey, A., 1992. A comparative analysis of non-offspring nursing. Anim. Behav. 43, 265-281.

Pobiner, B.L., Rogers, M.J., Monahan, C.M., Harris, J.W.K., 2008. New evidence for hominin carcass processing strategies at $1.5 \mathrm{Ma}$, Koobi Fora, Kenya. J. Hum. Evol. 55, 103-130.

Pontzer, H., Rolian, C. Rightmire, G.P. Jashashvili, T, de Leon, M.S.P. Lordkipanidze, D., Zollikofer, C.P.E., 2010. Locomotor anatomy and biomechanics of the Dmanisi hominins. J. Hum. Evol. 58, 492-504.

Portmann, A., 1962. Cerebralisation und ontogenese. Medizinische Grundlagenforschung 4,1-62.

Revell, L.J., 2009. Size-correction and principal components for interspecific comparative studies. Evolution 63, 3258-3268.

Rightmire, G.P., Lordkipanidze, D., Vekua, A., 2006. Anatomical descriptions, comparative studies and evolutionary significance of the hominin skulls from Dmanisi, Republic of Georgia. J. Hum. Evol. 50, 115-141.

Ross, C., 2003. Life history, infant care strategies, and brain size in primates. In: Kappeler, P.M., Pereira, M.E. (Eds.), Primate Life Histories and Socioecology. University of Chicago Press, Chicago, pp. 266-284.

Ross, C., MacLarnon, A., 2000. The evolution of non-maternal care in anthropoid primates: a test of the hypotheses. Folia Primatol. 71, 93-113.

Rubenstein, D.R., Lovette, I.J., 2007. Temporal environmental variability drives the evolution of cooperative breeding in birds. Curr. Biol. 17, 1414-1419.

Ruffer, D.G., 1965. Sexual behavior of the northern grasshopper mouse (Onychomys leucogaster). Anim. Behav. 13, 447-452.

Ruffer, D.G., 1968. Agonistic behavior of the northern grassshopper mouse (Onychomys leucogaster breviauritus). J. Mammal. 49, 481-487.

Russell, A.F., Langmore, N.E., Cockburn, A., Astheimer, L.B., Kilner, R.M., 2007. Reduced egg investment can conceal helper effects in cooperatively breeding birds. Science 317, 941-944.

Scantlebury, M., Russell, A.F., Mcllrath, G.M., Speakman, J.R., Clutton-Brock, T.H 2002. The energetics of lactation in cooperatively breeding meerkats Suricata suricatta. Proc. R. Soc. Lond. B 269, 2147-2153.

Schultz, A.H., 1949. Ontogenetic specializations of man. Arch. Julius Klaus Stift Vererbungsforsch. Sozialanthropol. Rassenhyg. 24, 197-216.

Sellen, D.W., 2007. Evolution of infant and young child feeding: implications for contemporary public health. Annu. Rev. Nutr. 27, 123-148.

Silk, J.B., 2007. The adaptive value of sociality in mammalian groups. Philos. Trans. $R$ Soc. B 362, 539-559.

Singer, D., Mühlfeld, C., 2007. Perinatal adaptation in mammals: the impact of metabolic rate. Comp. Biochem. Phys. A 148, 780-784.

Skinner, M.M., Wood, B., 2006. The evolution of modern human life history. In: Hawkes, K., Paine, R.R. (Eds.), The Evolution of Human Life History. School of American Research Press, Santa Fe, pp. 331-400.

Snowdon, C.T., 1996. Infant care in cooperatively breeding species. Adv. Stud. Behav. $25,643-689$. 
Solomon, N.G., French, J.A. (Eds.), 1997. Cooperative Breeding in Mammals. Cambridge University Press, Cambridge.

Speakman, J.R., 2008. The physiological costs of reproduction in small mammals. Philos. Trans. R. Soc. B 363, 375-398.

Spencer-Booth, Y., 1970. The relationships between mammalian young and conspecifics other than mothers and peers: a review. Adv. Stud. Behav. 3, 119-194.

Trevathan, W., 1987. Human Birth: An Evolutionary Perspective. Aldine, Chicago.

van Schaik, C.P., Burkart, J.M., 2010. Mind the gap: cooperative breeding and the evolution of our unique features. In: Kappeler, P.M., Silk, J. (Eds.), Mind the Gap: Tracing the Origins of Human Universals. Springer, Berlin, pp. 477-496.

van Schaik, C.P., Burkart, J.M., 2011. Social learning and evolution: the cultural intelligence hypothesis. Philos. Trans. R. Soc. B 366, 1008-1016.

van Woerden, J.T., van Schaik, C.P., Isler, K., 2010. Effects of seasonality on brain size evolution: evidence from strepsirrhine primates. Am. Nat. 176, 758-767. van Woerden, J.T., Willems, E.P., van Schaik, C.P., Isler, K., 2012. Large brains buffer energetic effects of seasonal habitats in catarrhine primates. Evolution 66,191-199.

Washburn, S.L., 1960. Tools and human evolution. Sci. Am. 203, 63-75.

Whitten, P.L., 1987. Infants and adult males. In: Smuts, B.B., Cheney, D.L., Seyfarth, R.M., Wrangham, R.W., Struhsaker, T.T. (Eds.), Primate Societies. University of Chicago Press, Chicago, pp. 343-357.

The handbook of the mammals of the world. In: Wilson, D.E., Mittermeier, R.A. (Eds.), Carnivores, vol. 1. Lynx Edicions, Barcelona.

Wilson, D.E., Reeder, D.M. (Eds.), 2005. Mammal Species of the World. A Taxonomic and Geographic Reference, third ed. Johns Hopkins University Press, Washington, D.C.

Woodroffe, R., Vincent, A., 1994. Mother's little helpers: patterns of male care in mammals. Trends Ecol. Evol. 9, 294-297.

Zenuto, R.R., Antinuchi, C.D., Busch, C., 2002. Bioenergetics of reproduction and pup development in a subterranean rodent (Ctenomys talarum). Physiol. Biochem. Zool. 75, 469-478. 